\title{
Management of Obesity and Nonalcoholic Fatty Liver Disease: A Literature Review
}

\author{
Anas Hashem, MD ${ }^{1}$ Amani Khalouf, $\mathrm{MD}^{1}$ Andres Acosta, MD, PhD ${ }^{1}$ \\ ${ }^{1}$ Division of Gastroenterology and Hepatology, Department of \\ Medicine, Precision Medicine for Obesity Program, Mayo Clinic, \\ Rochester, Minnesota

\begin{abstract}
Address for correspondence Andres Acosta, MD, PhD, Mayo Clinic, Charlton 8-142, 200 First St. S.W., Rochester, MN 55905

(e-mail: acosta.andres@mayo.edu).
\end{abstract}

Semin Liver Dis 2021;41:435-447.

\begin{abstract}
Keywords

- nonalcoholic fatty liver disease

- nonalcoholic steatohepatitis

- obesity

- weight loss

- bariatric surgery

With the recent urbanization and globalization, the adult obesity rate has been increasing, which was paralleled with a dramatic surge in the incidence and prevalence of nonalcoholic fatty liver disease (NAFLD). NAFLD poses a growing threat to human health as it represents the most common cause of chronic liver disease in developed countries. It encompasses a wide spectrum of conditions starting from a build-up of fat in hepatocytes (steatosis), to developing inflammation (steatohepatitis), and reaching up to cirrhosis. It is also associated with higher rates of cardiovascular mortalities. Therefore, proper timely treatment is essential and weight loss remains the cornerstone in the treatment of obesity-related liver diseases. When diet, exercise, and lifestyle changes are not successful, the current recommendation for weight loss includes antiobesity medications and bariatric endoscopic and surgical interventions. These interventions have shown to result in significant weight loss and improve liver steatosis and fibrosis. In the current literature review, we highlight the expected outcomes and side effects of the currently existing options to have a weightcentric NAFLD approach.
\end{abstract}

Obesity is defined as the excessive accumulation of fat in the adipose tissue throughout the body. It represents a complex and multifactorial disease with multiple adverse effects on human health. ${ }^{1}$ Obesity is ranked as the second most common preventable risk factor for overall death, after smoking. ${ }^{2}$ When comparing the all-cause mortality between patients with normal body weight and those with obesity, the hazard ratio for severe obesity was $1.29 .^{3}$ Due to the significant rise in its incidence and prevalence, obesity is now regarded as "the single greatest threat to public health for the United States of America (USA)."1 The most recent statistics from the Center for Disease Control and Prevention (CDC) reveal an increase in obesity prevalence within the past 18 years, from $30.5 \%$ in 1999 to 2000 to $42.4 \%$ in 2017 to $2018,4,5$ and according to the direst projections, $50 \%$ of the United States population will have obesity by $2030 .^{6}$ This, by no doubt, would translate into a remarkable rise in obesity-related comorbidities which include diabetes mellitus (DM), hypertension, cardiovascular diseases, and nonalcoholic fatty liver disease (NAFLD), among others. ${ }^{7}$ Consequently, evidence has shown that obesity increases the risk of developing liver diseases, particularly NAFLD (relative risk [RR] 4.6 [95\% confidence interval or CI 2.5-11.0]), cirrhosis (RR 4.1 [95\% CI 1.4-11.4]) and hepatocellular carcinoma (RR 1.89 [95\% CI $1.5-2.4]){ }^{7}$ It also plays a significant role in determining the prognosis of other liver diseases, like viral hepatitis, as it diminishes the response to treatment by hindering the fibrosis improvement. ${ }^{8}$

\section{Nonalcoholic Liver Disease}

The hepatic manifestation of metabolic syndrome presents in the form of NAFLD, which is the leading cause of chronic liver disease in the United States. ${ }^{9}$ Based on multiple epidemiological studies, the prevalence rate of NAFLD in United States and North America is 21 to $24.7 \%{ }^{10}$ while the annual published online

July 9,2021
DOI https://doi.org/ 10.1055/s-0041-1731704. ISSN $0272-8087$.

\footnotetext{
(C) 2021. The Author(s).

This is an open access article published by Thieme under the terms of the Creative Commons Attribution-NonDerivative-NonCommercial-License, permitting copying and reproduction so long as the original work is given appropriate credit. Contents may not be used for commercial purposes, or adapted, remixed, transformed or built upon. (https://creativecommons.org/ licenses/by-nc-nd/4.0/)

Thieme Medical Publishers, Inc., 333 Seventh Avenue, 18th Floor, New York, NY 10001, USA
} 
incidence is 2.2 to $3.2 \% .{ }^{11}$ This prevalence is even higher among people with obesity (up to $90 \%)^{12}$ and type 2 DM (T2DM) (59.67\%). ${ }^{13}$ It encompasses a wide clinical and histological spectrum ranging from mild hepatic steatosis to the more severe forms of nonalcoholic steatohepatitis (NASH), leading to hepatic fibrosis, cirrhosis, and hepatocellular carcinoma. The exclusion of other liver disease causes, such as excessive alcohol intake, is essential for diagnosis. ${ }^{14}$ NAFLD pathogenesis follows a series of liver insults, known as the "multi-hit hypothesis." ${ }^{14}$ In genetically predisposed subjects, insulin resistance marks the beginning of the chain, activating B-oxidation and adipose tissue lipolysis, which results in free radical injury to the hepatic cells. It promotes the production of proinflammatory cytokines with a worsening cycle of inflammation, necrosis, and fibrosis. ${ }^{14}$

The diagnosis of NAFLD necessitates the presence of proof for the excessive accumulation of fatty acids in the hepatocytes, by either imaging or direct visualization under microscopy. ${ }^{15}$ However, some "noninvasive" scoring systems have been developed. ${ }^{15}$ The National Institutes of Health's NASH Committee ${ }^{16}$ formulated a NAFLD severity score called NAFLD Activity Score (NAS). The NAS is a numerical grading system, calculated according to the severity level of each of three defining histological features. These include: (1) severity of steatosis (0-3), (2) hepatocellular ballooning (0-2), and (3) lobular inflammation (0-3). ${ }^{16}$ The final score represents the sum of each element, ranging from 0 to 8 . A reduction in the NAS marks a refinement in the histological features toward the resolution. ${ }^{16}$ Another noninvasive scoring system for liver fibrosis is the nonalcoholic fatty liver disease fibrosis score (NFS), which utilizes routinely measured clinical and biochemical laboratory findings. ${ }^{17}$ However, the low sensitivity and specificity of NFS in diagnosing NAFLD fibrosis necessitates further diagnostic modalities. Imaging tests are considered acceptable forms of noninvasive testing with relatively higher detection accuracy. Imaging modalities, such as ultrasound-based transient elastography (USTE) and magnetic resonance (MR) elastography, can detect the level of liver stiffness. ${ }^{18,19}$ A meta-analysis of seven studies conducted to measure USTE accuracy revealed the presence of a direct relationship between the NAFLD stage on biopsy and the USTE sensitivity and specificity levels. ${ }^{18}$ On the other hand, MR elastography can be used to both diagnose and grade NAFLD. ${ }^{19}$ According to another meta-analysis, the sensitivity and specificity of MRE reach up to 82.3 and $86.9 \%$, respectively. ${ }^{20}$ Despite the impracticality and invasiveness, puncture liver biopsy remains the gold standard diagnostic test for NAFLD, with the highest sensitivity and specificity amongst all. ${ }^{21}$

With the increased detection rate of NAFLD, management practices are focused on preventing the development of steatohepatitis (NASH) and hepatic fibrosis and reducing the risk of any NAFLD-associated cardiovascular comorbidities. According to a population-based cohort study, ${ }^{22}$ NAFLD acts as an independent risk factor for cardiovascular mortality, mandating further cardiovascular risk control in these patients. ${ }^{22}$ Interestingly, Ampuero et $\mathrm{al}^{23}$ also followed metabolically healthy patients with NAFLD for
15 years and observed that those with a significant level of hepatic fibrosis were at a higher risk of developing metabolic conditions such as T2DM (HR $=2.95, p=0.019)$ and hypertension $(\mathrm{HR}=2.39, p=0.028)$. They had fourtimes higher incidence rate than those with mild fibrosis. ${ }^{23}$ Therefore, early initiation of NAFLD treatment reduces the risk of worsening hepatic inflammation with better overall health outcomes. Given the fact that obesity and metabolic syndrome are regarded as the main key players in the development of NAFLD, efforts toward weight reduction and improving the metabolic profile highlight the most beneficial interventions and remain the cornerstone of NAFLD treatment. ${ }^{24}$ The suggested therapeutic approach begins with lifestyle modification (diet and exercise), and if sufficient and sustained weight loss is not achieved, secondlevel therapies (e.g., antiobesity medications, bariatric endoscopic and surgical procedures) may be used to enhance the overall effect. ${ }^{25}$ Strong evidence suggested that a 5 to $10 \%$ loss of the initial body weight led to a recovery in the histological findings of NAFLD. ${ }^{26}$ In this review study, we aim to shed light on the feasibility and sustainability of various obesity management approaches and their consequence on related liver diseases.

\section{Management of Obesity in Patients with NAFLD}

\section{Lifestyle Modifications (Cornerstone of Treatment)}

The cornerstone of NAFLD management is weight loss. ${ }^{27}$ This requires adopting an energy restrictive lifestyle that includes a decrease in oral caloric intake and an increase in the body's energy expenditure. According to multiple randomized-controlled trials (RCTs), ${ }^{27-34}$ weight loss in NAFLD patients led to an improvement in hepatic triglyceride contents (determined using an MR) and in NAS (determined by liver biopsy) with an accompanied reduction in cardiovascular risk factors such as insulin resistance and the level of serum lipid. ${ }^{27-34}$ According to Musso et $\mathrm{al}^{35}$ a weight loss of $\geq 7 \%$ led to significant positive outcomes in histological findings and cardiometabolic profile. ${ }^{35}$ Patients with biopsy-proven steatohepatitis (NASH) should aim for a higher percentage of weight loss than patients with steatosis (NAFLD); it is recommended that in NASH the weight loss goal should be close to $10 \%{ }^{35}$

Current guidelines endorse that to achieve weight loss, an energy deficit is essential. Limiting dietary energy intake below that required for energy balance can be achieved through a reduction of daily calories to 1,200 to 1,500 for women, and 1,500 to 1,800 for men (kilocalorie levels are usually adjusted for the individual's body weight and physical activity levels); or estimation of individual daily energy requirements and prescription of an energy deficit of 500 or $750 \mathrm{kcal} / \mathrm{d} .^{25}$ As a proof, Vilar-Gomez et al conducted a prospective study over 52 weeks on 293 subjects. These subjects were encouraged to adopt a healthy lifestyle to reduce their body weight. ${ }^{36}$ By the end of the study, $30 \%$ had lost $\geq 5 \%$ of their weight. While comparing body weight loss with improvement in NASH-related 
histological parameters, weight loss was found to be an independent factor (Odds ratio $=1.1-2.0 ; p<0.01$ ). Twentyfive per cent of these subjects achieved NASH resolution, $47 \%$ had a reduction in NAS score, and $19 \%$ had complete fibrosis regression. ${ }^{36}$ Despite the ongoing controversies, the macronutrient composition of the diet does not influence the total body weight loss (TBWL) in large population studies, signifying the low-calorie and diet-adherence remain the key factors for successful weight loss. ${ }^{37}$ Meanwhile, the main obstacle in lifestyle modifications is putting the patient in a negative energy balance to achieve an ideal weight and sustain it. Thus, finding an alternative therapeutic approach independent of weight loss will be favored.

Some of the recently published studies have highlighted the potential plausible effect of the macronutrient composition of the Mediterranean Diet (MedDiet) in resolving NAFLD, independent of accompanying weight loss. ${ }^{38}$ The MedDiet is a well-known dietary pattern in the Mediterranean countries and is mainly characterized by a high intake of plant-based and fiber-rich foods, like vegetables, fruits, whole grains and nuts, along with a moderate intake of protein-rich lean meats like poultry and fish. ${ }^{39}$ Also, it is rich in monounsaturated fatty acids mainly from olive and olive oil and low in red meat consumption. ${ }^{39}$ A promising crossover study was conducted by Ryan et $\mathrm{al}^{40}$ to examine the effect of MedDiet, when compared with low fat-high carbohydrate diet (LF-HCD), on NAFLD regression. After randomizing and matching both groups, all potential confounders such as physical activity, abdominal obesity, mean serum glucose, and insulin sensitivity were excluded. Despite the lack of significant difference in weight loss between the two dietary groups $(p=0.1)$, the changes in NAFLD and insulin sensitivity were significant. The mean reduction of liver fat was $39 \pm 4 \%$ in the MedDiet group when compared with only $7 \pm 2 \%$ in the LF-HCD $(p=0.03)$. Moreover, circulating insulin concentration declined significantly in MedDiet $(p=0.003)$, suggesting an enhancement in insulin sensitivity. ${ }^{40}$ Further, an interesting study with a larger cohort of participants ( $n=94)$ is currently being conducted aiming to examine the sustainability of these metabolic changes after 12 months follow-up. ${ }^{38}$

Along with the prescription for a reduced-calorie diet, a comprehensive lifestyle intervention program should advocate of increasing aerobic physical activity for $\geq 150 \mathrm{~min}$ per week (such as brisk walking for $\geq 30 \mathrm{~min} / \mathrm{d}$ most days of the week), and a goal of $>10,000$ steps per day. Higher levels of physical activity, approximately 200 to 300 minutes per week, are recommended to maintain weight loss or minimize weight regain for long term ( $>1$ year). ${ }^{41}$ Diet and physical activity recommendations can be in combination with a hospital/university or commercial behavioral programs; these are usually comprehensive lifestyle interventions that provide structured behavior strategies to facilitate adherence to diet and activity recommendations. These strategies include regular self-monitoring of food intake, body weight, physical activity, and food cravings. These same behaviors are recommended to maintain lost weight, with

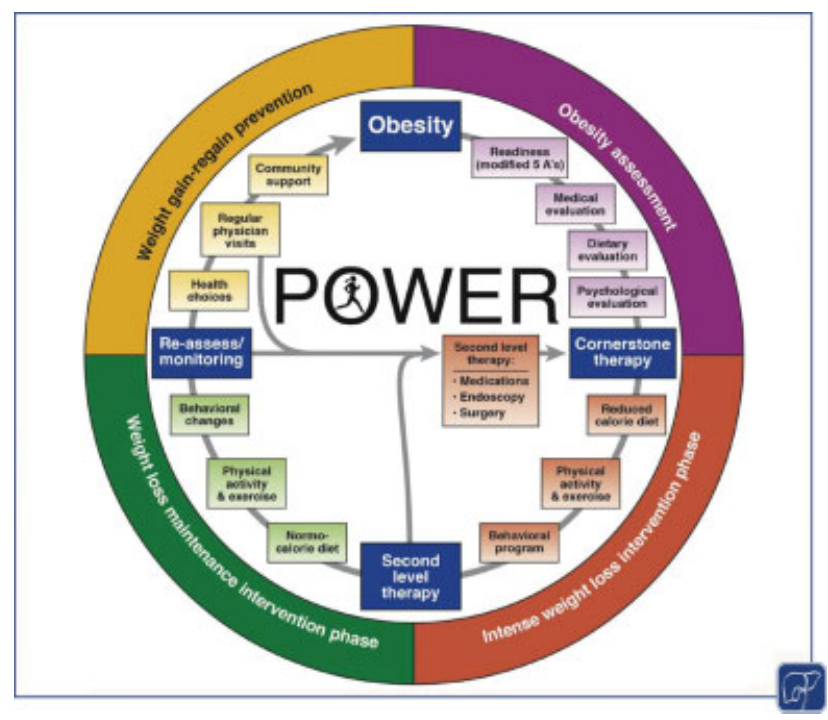

Fig. 1 Practice Guide on Obesity and Weight Management, Education, and Resources (POWER) for representing the continuous management of obesity. Introducing four main stages of obesity care and the need to introduce second-level therapies. ${ }^{25}$

the addition of frequent (i.e., weekly or more frequent) monitoring of body weight. ${ }^{42}$

Intense lifestyle interventions vary in outcomes and on average, most weight loss attempts with diet and exercise result in 30\% of the patients losing more than 5\% TBWL in 6 to 12 months. ${ }^{43}$ The reasons for the variability of response are attributed to many causes from diet adherence to metabolic adaptations that thwart weight loss attempts. ${ }^{44-46}$ Thus, it is essential to escalate obesity care via utilizing second-level therapies to achieve significant weight loss and to prevent weight regain (-Fig. 1). ${ }^{25}$ In this white paper endorsed by nine academic societies, ${ }^{25}$ the recommendation is to complement the cornerstone therapy of diet and exercise with antiobesity medications, bariatric endoscopy, and surgery to all the patients with obesity or obesity-related comorbidities who do not achieve successful weight loss with lifestyle alone.

\section{Antiobesity Medications}

Antiobesity medications (AOMs) approved by the Food and Drug Administration (FDA) for weight loss might be considered as the next line of treatment for obesity or obesity-related liver diseases. The FDA adopts a figure of at least $5 \%$ difference in mean weight loss of medication, compared with placebo, to be approved for the long-term use in patients with a body mass index $(\mathrm{BMI})>30 \mathrm{~kg} / \mathrm{m}^{2}$, or those with a BMI $>27 \mathrm{~kg} / \mathrm{m}^{2}$ and have one or more obesity-related comorbidities such as T2DM, hypertension, and dyslipidemia. ${ }^{47}$ The current AOMs approved for long-term use include phentermine/topiramate, orlistat, liraglutide, and bupropion/naltrexone reviewed in detail elsewhere. ${ }^{25}$ These medications achieved 6 to $11 \%$ TBWL over 12 months in conjunction with lifestyle modifications. $^{47}$ In theory, all the AOMs should result in NAFLD improvement based purely on their weight loss effect, however, only liraglutide and orlistat have been formally studied in liver disease (-Table 1). 


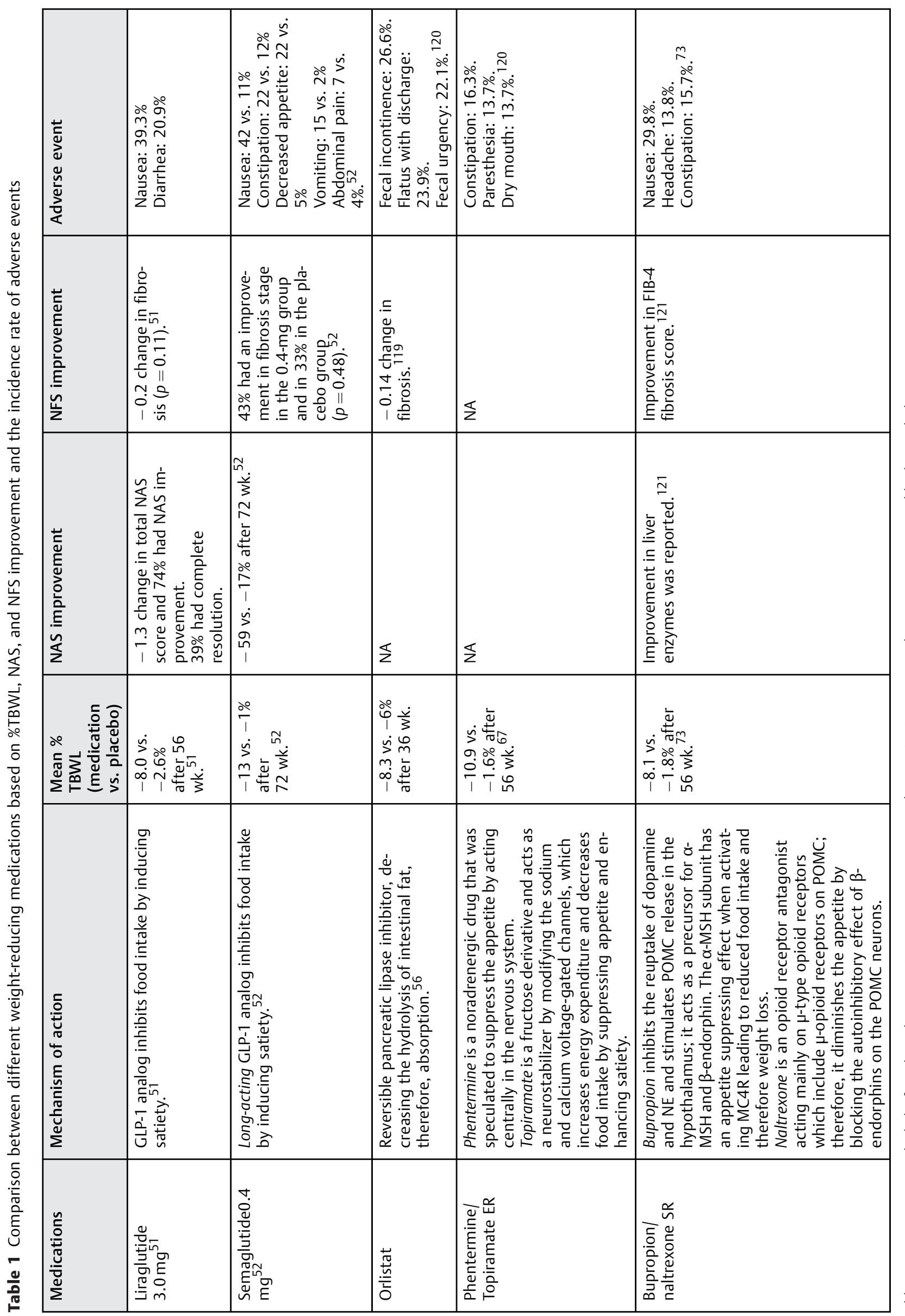




\section{GLP-1 Analogs}

GLP-1 is an endogenously produced, gut-derived incretin hormone. It augments insulin secretion by $\beta$-cells and reduces glucagon release. It also reduces gastric emptying and food intake. GLP-1 analogs, e.g., Liraglutide, have been initially FDA-approved in 2005 for the treatment of T2DM. ${ }^{48}$ In 2015, a large double-blinded RCT ( $n=3731)$ was conducted to study the efficacy of $3.0 \mathrm{mg}$ liraglutide on weight loss, compared with placebo. The liraglutide group achieved a mean weight loss of $8.4 \pm 7.3 \mathrm{~kg}$ compared with $2.8 \pm 6.5 \mathrm{~kg}$ only $(p<0.001)$ in the placebo group. $63.2 \%$ of the candidates in the liraglutide group lost more than $5 \%$ of their body weight as compared with $27.1 \%$ in the placebo group $(p<0.001) .{ }^{49}$ Following multiple similar RCTs, liraglutide was approved by the FDA in December 2014 for weight loss. $^{50}$ In addition, another 48-week double-blinded RCT called "LEAN" trial ${ }^{51}$ was conducted to objectively measure the effect of $3.0 \mathrm{mg}$ liraglutide on NASH. The study showed that $39 \%$ (nine out of 23 ) patients on liraglutide versus $9 \%$ (two out of 22) patients on placebo had complete resolution of NASH without worsening of fibrosis based on the end-oftreatment liver biopsy and histological findings. ${ }^{51}$ Additionally, 19 (83\%) of liraglutide group versus 10 (45\%) had improvement in steatosis with a significant difference between the groups $(p=0.009)$. The level of improvement in fibrosis was not significant ( $p=0.46$ ); however, the worsening in fibrosis was more prominent $(p=0.04)$ in the placebo group (36\%) compared with the liraglutide (9\%). ${ }^{51}$ GLP-1 analogs demonstrated potency in enhancing insulin sensitivity and reducing body weight; thus, improving the overall outcome in patients with NAFLD and NASH.

Recently, in a double-blinded RCT conducted over 72 weeks, a similar long-acting GLP-1 receptor agonist, $0.4 \mathrm{mg}$ of semaglutide, showed a significant reduction in mean body weight of $13 \%$ in the treatment groups versus $1 \%$ in placebo. The improvement of NASH was $59 \%$ of patients in the treatment group versus $17 \%$ in the placebo group $(p<0.001) .{ }^{52}$ However, the amelioration in the fibrosis stage was not significant between both groups as it was $43 \%$ in the treatment group and $33 \%$ in the placebo group $(p=0.48){ }^{52}$ These findings promote liraglutide-or other GLP-1 analogsas an attractive medication(s) to consider in patients with NASH.

\section{Orlistat (Xenical)}

Gastric and pancreatic lipases are secreted into the alimentary tracts and play important roles in the digestion of dietary fat. These enzymes hydrolyze triglycerides into absorbable free fatty acid chains and a monoglyceride. Orlistat acts locally by reversibly inhibiting gastric and pancreatic lipases through forming covalent bonds with the serine residues of the lipase active sites rendering them inactive. The recommended dosage of orlistat ( $120 \mathrm{mg}$ capsule TID) reduces dietary fat absorption by around 30\% and improves insulin resistance. ${ }^{53}$ According to a systematic review, ${ }^{54}$ orlistat is effective for improving serum lipid profiles, including total cholesterol, LDL, and HDL cholesterols, in patients with obesity and with/without diabetes. ${ }^{54}$ Multiple studies $^{55-58}$ have investigated the effect of orlistat use and dietary modifications on NAFLD, and all of them reported improvement in the liver enzymes (aspartate aminotransferase [ALT] and alanine aminotransferase [AST]) and liver fat content based on liver histopathology. ${ }^{55-58}$ Patients who used orlistat for at least 24 weeks had improvement of their hepatic profile (biopsy and enzymes) with 5 to $10 \%$ weight loss, in all five studies. Interestingly, an RCT conducted over 24 weeks, assessed the efficacy of orlistat in the treatment of NAFLD on 52 subjects. Both groups had a similar amount of significant weight loss with no differences between groups $(p=0.5)$. However, an almost twofold reduction in the serum levels of ALT and AST occurred in the orlistat group. In addition, reversal of fatty liver by ultrasound was observed in the orlistat group with no significant difference in the degree of steatosis and fibrosis between both groups. ${ }^{59}$

On the contrary, Harrison et al, ${ }^{56}$ conducted a 36-week double-blinded RCT to assess the efficacy $120 \mathrm{mg}$ TID orlistat to treat NASH on 41 patients. All participants were instructed to have their level of physical activities without recommending a specific type of exercise. The outcomes of this study were: (1) an overall mean weight loss of $8.3 \%(p<0.001)$ and (2) reduction in serum ALT from a mean of $108 \pm 95 \mathrm{IU} / \mathrm{L}$ to $53 \pm 41 \mathrm{IU} / \mathrm{L}(p<0.001)$ and AST from $64 \pm 39 \mathrm{IU} / \mathrm{L}$ to $36 \pm 17$ $\mathrm{IU} / \mathrm{L}(p<0.001)$ when compared with baseline. However, no statistically significant difference in weight loss was detected between both groups $(p=0.85)$. Harrison et al concluded that orlistat improvement in NAFLD is weight loss dependent. ${ }^{56}$

\section{Phentermine/Topiramate Extended Release (Qsymia)}

Phentermine is a noradrenergic drug that was speculated to suppress appetite by acting centrally in the nervous system to enhance norepinephrine (NE) release and reuptake. It has been approved in the United States to treat obesity since 1959 with the therapeutic dosage ranging from 15 to $37.5 \mathrm{mg}$ per day. ${ }^{60}$ It does not have any serotonergic or dopaminergic activities, therefore, it possesses a lesser risk for addiction as compared with amphetamines. ${ }^{61}$ On the other hand, Topiramate is a fructose derivative which acts as a neurostabilizer by modifying the sodium and calcium voltage-gated channels. It has been used as an antiepileptic in 1996 and for migraine prophylaxis in $2004 .^{62}$ Topiramate was found to induce weight loss as a side effect. Further studies were performed to evaluate the efficacy of these medications in reducing body weight. ${ }^{63}$ The proposed theory behind this effect was the increase in energy expenditure, promoting satiation, and suppressing appetite. ${ }^{64}$

Phentermine/topiramate extended release is a combination that has been approved by the FDA in 2012 for weight loss. ${ }^{65}$ These two medications combined reduce appetite and enhance satiation. ${ }^{66}$ Two large RCTs, the EQUIP and the CONQUER trials were conducted to study the efficacy of phentermine/topiramate extended release on weight loss with large sample sizes of 1,267 and 2,487, respectively. ${ }^{65}$ According to the EQUIP study, 25.5, 13.0, and 5.9\% for the placebo group participants were able to achieve a weight reduction of 5, 10, and 15\%, respectively. However, 59.1, 27.7, and $12.4 \%$ of the candidates who received $3.75 / 23 \mathrm{mg}$ of 
phentermine/topiramate extended release attain these targets. A higher dosage of $15 / 92 \mathrm{mg}$ was associated with larger figures up to $83.5,67.7$, and $48.1 \%$, respectively (between groups, $p<0.001) .{ }^{67}$ Currently, there are no available studies in PUBMED that investigate the direct efficacy of phentermine/topiramate extended release on NAFLD or NASH. However, indirect effects on the course of NAFLD are rather speculated, given their efficacy in weight loss. Further RCT studies are required to objectively establish the relationship between phentermine/topiramate extended release and NAFLD.

\section{Bupropion/Naltrexone Sustained Release (Contrave)}

Bupropion/Naltrexone sustained release is a combination of two drugs, Bupropion and Naltrexone. Bupropion is a centrally acting drug that inhibits the reuptake of dopamine and $\mathrm{NE}$, which will stimulate the proopiomelanocortin (POMC) release in the arcuate nucleus of the hypothalamus; it acts as a precursor of the two subunits, $\alpha$-melanocyte-stimulating hormone $(\alpha-\mathrm{MSH})$ and $\beta$-endorphin (opioid). ${ }^{68}$ The $\alpha$-MSH subunit has an appetite suppressing effect when activating melanocortin-4 receptors (MC4R) leading to reduced food intake and therefore weight loss. However, this weight loss does not exceed $5 \%$ of the total body weight even on longterm use. ${ }^{69}$ The suggested limitation in the efficacy of weight loss is due to the autoinhibitory feedback on $\mu$-opioid receptors of the POMC neurons by the action of the $\beta$ endorphins subunit. Primarily, bupropion has been used to treat patients with depression or for smoking cessation with a daily dosage of $300 \mathrm{mg} \cdot{ }^{69,70}$ In contrast, naltrexone is an opioid receptor antagonist acting mainly on $\mu$-type opioid receptors. It is primarily used to treat the dependence on alcohol and opioids. As a side effect, it diminishes the appetite by blocking the autoinhibitory effect of $\beta$-endorphins on the POMC neurons. Thus, the unsuppressed action of $\alpha-\mathrm{MSH}$ on the MC4R results in weight loss. ${ }^{69}$

In September 2014, bupropion/naltrexone sustained release was approved by the FDA for weight loss in adult patients with obesity (BMI $\geq 30 \mathrm{~kg} / \mathrm{m}^{2}$ ) with/without comorbidities or in overweight patients (BMI $\geq 27 \mathrm{~kg} / \mathrm{m}^{2}$ ) with weight-related comorbidities. ${ }^{71,72}$ Contrave Obesity Research I (COR-I) multicentric randomized trial was performed on 1,682 participants to study the efficacy of bupropion/naltrexone sustained release on weight loss over a period of 56 weeks. In patients taking bupropion (360 mg) naltrexone (32 $\mathrm{mg}$ ) sustained release daily had an overall $-8.1 \%$ change in their body weight upon the completion of the study when compared with the placebo group $(p<0.0001){ }^{73}$ A study $^{74}$ of 781 subjects to measure the effect of the medication on liver enzymes revealed the presence of a positive linear correlation between the level of weight loss and reduction in ALT $(r=0.396, p<0.001) .{ }^{74}$ These results suggest the presence of positive outcomes when using bupropion/naltrexone sustained release to treat obesity and obesity-related liver diseases (NAFLD). Bajaj et al ${ }^{75}$ confirmed these findings in a post-hoc analysis of four RCTs, demonstrating a significant improvement in the ALT and fibrosis index $(p<0.0001){ }^{75}$ However, bupropion/naltrexone sustained release has not been studied prospectively in biopsy-proven NAFLD or NASH and such studies are needed.

\section{Procedural Interventions}

As previously stated, lifestyle changes still mark the backbone of nonalcoholic steatosis and hepatitis management, mainly targeting a sustained long-term weight loss. The threshold for obtaining a meaningful improvement in the liver profile is set as 7 to $10 \%$ TBWL. However, only $30 \%$ of patients on lifestyle changes accomplish this goal, ${ }^{43}$ which they rarely maintain for an adequate duration to allow full recovery of the liver. ${ }^{76}$ Consequently, more advanced invasive approaches are needed, especially in those with initial failure of NAFLD amelioration. Bariatric endoscopic and surgical procedures have significantly higher levels of sustainable weight loss when compared with lifestyle modifications only. ${ }^{77}$ Preliminary data shows promising results in reversing hepatic steatosis, steatohepatitis, and regression of fibrosis in $30 \%$ of patients. $^{78}$

\section{Bariatric Endoscopic Interventions}

Recently, endoscopic bariatric therapy (EBT) has emerged as an alternative to the more invasive and traditional bariatric surgeries. It is performed using a flexible gastrointestinal endoscopic tube inserted into the oral opening reaching the upper gastrointestinal tract. ${ }^{79}$ EBT proves to be efficient in reducing body weight and serves as a safe alternative for those failing lifestyle and pharmacological measures especially with mild-to-moderate obesity (BMI range 30-40 $\mathrm{kg} / \mathrm{m}^{2}$ ) without comorbidities. ${ }^{80}$ EBTs are reviewed in detail elsewhere. ${ }^{79}$ Theoretically, EBTs might be one of the safest, least invasive, and most efficient procedures to treat patients with NAFLD ( - Table 2 ). In this section, we will briefly cover the most useful and validated studies available in the literature on the effect of these procedures on NAFLD.

\section{Endoscopic Intragastric Balloon}

Intragastric balloon (IGB) is a space-occupying endoscopic procedure that results in weight loss through reducing the preprandial sense of hunger, increasing the intrameal satiation, and delaying gastric emptying to enhance postprandial satiety, thus, endorsing weight loss. ${ }^{81}$ The balloons are inserted in the stomach, and then filled with either air or a normal saline solution. Usually, normal saline-containing balloons provide better outcomes as they produce both, volume and weight effects inside the stomach, which will further affect the satiety and satiation in those patients. ${ }^{82}$ On August 5, 2015, FDA approved the use of BioEnterics Intragastric Balloon (Orbera) for weight loss. ${ }^{83,84}$ Recently, in March 2021, Apollo Endosurgery received a Breakthrough Device Designation from the U.S. FDA for the use of Orbera in treating patients with BMI between 30 and $40 \mathrm{~kg} / \mathrm{m}^{2}$ and noncirrhotic NASH with liver fibrosis. ${ }^{85}$

Bazerbachi et $\mathrm{al}^{86}$ evaluated the effect of the single fluidfilled IGB on the metabolic and histologic features of NASH in 21 NAFLD patients. Following 6 months of IGB, the mean initial TBWL was $11.7 \%{ }^{86}$ Eighteen of 20 patients (90\%) had significant improvement in their NAS with a median of 3 
Table 2 Comparison between different weight-reducing bariatric endoscopic interventions based on \%TBWL, NAS, and NFS improvement and the incidence rate of adverse events

\begin{tabular}{|c|c|c|c|c|c|}
\hline $\begin{array}{l}\text { Endoscopic } \\
\text { intervention }\end{array}$ & Procedure & Mean \%TBWL & NAS improvement & NFS improvement & Adverse Event (\%) \\
\hline $\begin{array}{l}\text { Endoscopic } \\
\text { intragastric } \\
\text { balloon }\end{array}$ & $\begin{array}{l}\text { Introducing an emp- } \\
\text { ty balloon into the } \\
\text { stomach through an } \\
\text { upper endoscopy. } \\
\text { Then, the balloon is } \\
\text { inflated with air or } \\
\text { saline to reduce the } \\
\text { stomach volume. } \\
\text { This will result in } \\
\text { early satiety and } \\
\text { weight loss. } \\
\text {.5 }\end{array}$ & $\begin{array}{l}-11.7 \pm 7.7 \% \\
\text { after } 6 \text { mo. }\end{array}$ & $\begin{array}{l}90 \% \text { had }-3 \text { points } \\
\text { improvement in } \\
\text { their NAS. }{ }^{66}\end{array}$ & $\begin{array}{l}-1.17 \text { stages im- } \\
\text { provement in } 15 \% \\
\text { of participants in } \\
\text { NFS. }{ }^{66}\end{array}$ & $\begin{array}{l}\text { Abdominal pain } \\
(33.7 \%) \\
\text { Nausea }(29 \%) \\
\text { GERD }(18.3 \%) \\
\text { Erosion }(12 \%) \\
\text { Early removal }(7.5 \%) \\
\text { Others (ulceration, } \\
\text { migration and small } \\
\text { bowel obstruction) } \\
(3.7 \%) .89\end{array}$ \\
\hline $\begin{array}{l}\text { Endoscopic } \\
\text { sleeve } \\
\text { gastroplasty }\end{array}$ & $\begin{array}{l}\text { A minimally invasive } \\
\text { bariatric procedure } \\
\text { that is done through } \\
\text { endoscopically } \\
\text { inserting a suturing } \\
\text { device to remodel } \\
\text { the greater curvature } \\
\text { of the stomach. } 67\end{array}$ & $\begin{array}{l}-14.9 \% \text { after } \\
6 \text { mo. }\end{array}$ & $\begin{array}{l}-4.0 \text { points per } \\
\text { year using Hepatic } \\
\text { steatosis index } \\
(\mathrm{HSI}) .70\end{array}$ & $\begin{array}{l}20 \% \text { had significant } \\
\text { improvement in } \\
\text { NFS (from F3-F4 or } \\
\text { indeterminate to } \\
\text { F0-F2). }{ }^{70} \\
-0.3 \text { points annu- } \\
\text { ally following the } \\
\text { procedure. }^{70}\end{array}$ & $\begin{array}{l}\text { Overall incidence of } \\
\text { adverse events is } 2.2 \% \text {. } \\
\text { Pain and nausea re- } \\
\text { quiring hospitalization } \\
(1.08 \%) \text {. } \\
\text { Upper Gl bleeding } \\
(0.56 \%) \text {. } \\
\text { Perigastric leak or col- } \\
\text { lection (0.48\%). } \\
\text { Pulmonary embolism } \\
(0.06 \%) \text {. } \\
\text { Pneumoperitoneum } \\
(0.06 \%) \text {. }\end{array}$ \\
\hline
\end{tabular}

Abbreviations: NAS, nonalcoholic fatty liver disease activity score; NFS, nonalcoholic fatty liver disease fibrosis score; TBWL, total body weight loss.

points reduction. Interestingly, liver fibrosis was improved by 1.17 stages in $15 \%$ of participants, while MR elastography revealed an improvement of 1.5 stages in $50 \%$ of patients. Their overall conclusion is that $50 \%$ of NAFLD patients achieved the FDA-approved level of impactful amelioration of NASH and regression in liver fibrosis. ${ }^{86}$ These positive outcomes reveal a promising long-standing intervention for patients with mild-to-moderate obesity. A thorough metaanalysis ${ }^{87}$ included 10 published studies on the impact of Orbera IGBs on NAFLD resolution, revealed a mean reduction in the participants' body weight of $11.9 \mathrm{~kg}$, with a significant $(p=0.03)$ histological improvement in NAS with a mean score of $2 \pm 0.75$ versus $4 \pm 2.25$ in the control sham group, after 6 months of follow-up. ${ }^{87}$ Also, Chandan et al $^{88}$ conducted a systematic review to evaluate the efficacy of Orbera IGB on NAFLD. The review included nine studies and shows that $79.2 \%$ of patients had improvement in steatosis while $83.5 \%$ improved in NAS score. All these promising data suggest a great future for the use of IGB in treating patients with NASH and NAFLD. While other IGBs may be beneficial for these conditions, further studies are needed. The effect of the other IGBs in weight loss is reviewed elsewhere. $^{79}$

IGBs are like any other procedural interventions, carry their own risks of complications and adverse events. According to a pooled study conducted by Abu Dayyeh et $\mathrm{al}^{89}$ of a manual review for 67 studies with 8,500 implantations, the most common adverse events of IGBs were abdominal pain (33.7\%), nausea (29\%), GERD (18.3\%), erosion (12\%), early removal (7.5\%), and others (ulceration, migration, and small bowel obstruction) (3.7\%). ${ }^{89}$

\section{Endoscopic Sleeve Gastroplasty}

Endoscopic sleeve gastroplasty (ESG) is an incisionless, minimally invasive bariatric endoscopy procedure that is done through inserting a suturing device attached to the endoscope to remodel the greater curvature. ${ }^{90}$ This reduces the gastric capacity and alters digestive physiology by inducing satiation. ${ }^{91}$ The efficacy of this procedure in achieving substantial weight loss has been well-studied. ${ }^{92}$ A systematic review and a meta-analysis of eight observational studies with 1,859 participants revealed a pooled \%TBWL of 14.9 , $16.4,16.8$, and $20 \%$, after $6,12,18$, and 24 months, respectively. ${ }^{93}$ Therefore, ESG has a strong potential to improve NAFLD and steatohepatitis. Hajifathalian et $\mathrm{al}^{94}$ also studied liver steatosis on 118 patients who underwent ESG and showed a mean weight loss of 14.6 and $15.5 \%$ in 6 months and 2 years, respectively. Surprisingly, $83 \%$ of patients had a TBWL of $\geq 7 \%$ at 2 years postoperatively and found a substantial regression in NAS scores $(p=0.034)$ with $20 \%$ of patients improving the risk for liver fibrosis from F3-F4 to F0-F2 ( $p=0.02) .{ }^{94}$ Several clinical trials are on-going to study the effect of ESG on NAFLD and NASH.

Regarding the most common adverse events following ESG, a thorough and comprehensive meta-analysis conducted by Hedjoudje et $\mathrm{al}^{95}$ showed promising findings. In nine large sample studies, the pooled incidence of severe post-ESG adverse event rate was $2.2 \%$. The incidence of pain 
Table 3 Comparison between different weight-reducing bariatric surgical interventions based on \%TBWL, NAS, and NFS improvement and the incidence rate of adverse events

\begin{tabular}{|c|c|c|c|c|c|}
\hline $\begin{array}{l}\text { Surgical } \\
\text { intervention }\end{array}$ & Procedure & Mean \%TBWL & $\begin{array}{l}\text { NAS improve- } \\
\text { ment }\end{array}$ & NFS improvement & Adverse event (\%) \\
\hline $\begin{array}{l}\text { Sleeve } \\
\text { gastrectomy }\end{array}$ & $\begin{array}{l}\text { A restrictive bariatric } \\
\text { procedure that } \\
\text { involves resection of } \\
\text { two-thirds of the } \\
\text { stomach's greater cur- } \\
\text { vature and gastric } \\
\text { fundus creating a long } \\
\text { tubular gastric conduit } \\
\text { running along the }_{\text {lesser curvature. }}{ }^{6}\end{array}$ & $\begin{array}{l}-31.7 \% \text { after } \\
6 \text { mo. }^{84}\end{array}$ & $\begin{array}{l}-2.3 \text { NAS score } \\
\text { improvement. }\end{array}$ & $\begin{array}{l}\text { Significant reduc- } \\
\text { tion in NFS of } \\
-0.7 .^{81}\end{array}$ & $\begin{array}{l}\text { Nutritional deficien- } \\
\text { cies ( } 7.4-30.5 \%) \text {. } \\
\text { Nondysplastic Bar- } \\
\text { rett's esophagus } \\
(15.16 \%) \\
\text { Choledocholithiasis } \\
(5.15 \%) \\
\text { Cholecystectomy } \\
(3 \%) .{ }^{87}\end{array}$ \\
\hline $\begin{array}{l}\text { Roux-en-Y } \\
\text { gastric } \\
\text { bypass }\end{array}$ & $\begin{array}{l}\text { A reconstructive pro- } \\
\text { cedure performed by } \\
\text { connecting a limb of } \\
\text { the small intestine to a } \\
\text { small gastric pouch } \\
\text { forming a shape of "Y." } \\
\text { Bypassing a portion of } \\
\text { the large stomach } \\
\text { pouch and proximal } \\
\text { small intestine reduces } \\
\text { the amount of } \\
\text { nutrients and calories } \\
\text { being absorbed. }\end{array}$ & $\begin{array}{l}-34.6 \% \text { after } \\
6 \text { mo. }^{84}\end{array}$ & $\begin{array}{l}\text { Improvement or } \\
\text { complete reso- } \\
\text { lution of steato- } \\
\text { sis, steatohepa- } \\
\text { titis by } 91 \text { and } \\
60 \% \text {, respective- } \\
\text { ly. }^{78} \\
-2.8 \text { NAS score } \\
\text { improvement. }\end{array}$ & $\begin{array}{l}31 \% \text { improvement } \\
\text { in NFS } 78 \\
-1.0 \text { reduction in } \\
\text { NFS score. }{ }^{79}\end{array}$ & $\begin{array}{l}\text { Cholelithiasis } \\
(32-42 \%) \\
\text { Nutritional deficien- } \\
\text { cies ( } 30-35 \%) \\
\text { Dumping syndrome } \\
(13 \%) \\
\text { Gastro-gastric fistula } \\
(1-2 \%) \\
\text { Small bowel obstruc- } \\
\text { tion }(1.5-5 \%) .88\end{array}$ \\
\hline
\end{tabular}

Abbreviations: NAS, nonalcoholic fatty liver disease activity score; NFS, nonalcoholic fatty liver disease fibrosis score; TBWL, total body weight loss.

and nausea required hospitalization (1.08\%), upper GI bleeding $(0.56 \%)$, perigastric leak or collection $(0.48 \%)$, pulmonary embolism and pneumoperitoneum (0.06\%). These results reinforce the safety of ESG in minimizing adverse events while achieving a significant weight loss along with noticeable improvement in obesity-related liver diseases. ${ }^{95}$

\section{Endoscopic Duodenal Mucosal Resurfacing}

Duodenum has been considered a targeted organ for weight loss. Favorable metabolic outcomes have been noticed when altering, excluding, or bypassing the duodenal exposure to intraluminal nutrients. ${ }^{96}$ Some human and animal studies have suggested that the duodenal surface plays a pivotal role in glucose hemostasis. ${ }^{97,98}$ Endoscopic duodenal mucosal resurfacing (DMR) is considered a minimally invasive procedure. The duodenal mucosa is separated from the submucosal layers by injecting normal saline, followed by circumferential hypothermal ablation of the mucosal layer. ${ }^{99}$ A direct relationship was observed between the length of the ablated duodenal segment and the improvement in metabolic profile. ${ }^{100}$ To further study the efficacy of DMR, de Oliveira et al ${ }^{101}$ conducted a meta-analysis embracing various metabolic variables (HbA1C, fasting plasma glucose, weight loss, liver enzymes, and hepatic steatosis). After 3 months of DMR, HbA1C levels have significantly dropped by $1.72 \%$ in 52 patients $(p=0.02)$. Whereas for weight loss, the mean weight reduction is $3.1 \mathrm{~kg}$ $(p<0.001)$. In terms of hepatic improvement, liver enzymes (ALT) and MRI-evident hepatic steatosis were significantly reduced $(p<0.001){ }^{101}$ These findings support the effectiveness of the DMR procedure in NAFLD resolution. Despite the lack of 5 to $7 \%$ mean of TBWL, hepatic improvement was still evident. This might suggest an alternative mechanism in which the duodenal mucosa and secreted incretin hormones play a role in the development of NAFLD. A study with a longer follow-up duration is required to evaluate the long-term metabolic effects of DMR procedures. Besides, this procedure should be compared with other endoscopic procedures to further validate its efficacy and study its feasibility in treating NAFLD. A further ongoing clinical trial is being conducted to study the safety and effectiveness of DMR in the treatment of T2DM. ${ }^{102}$

\section{Bariatric Surgical Intervention}

The effect of bariatric and metabolic surgeries in accomplishing sustainably significant weight loss and improvement in obesity-related comorbidities, including T2DM, HTN, and NAFLD, among others, has been well-studied. The popularity of these procedures has increased and reached up to 252,000 bariatric procedures performed in the United States in 2018. ${ }^{103}$ These procedures are indicated for severe obesity, patients with a BMI of $\geq 40 \mathrm{~kg} / \mathrm{m}^{2}$ or a BMI of $\geq 35 \mathrm{~kg} / \mathrm{m}^{2}$ associated with obesity-related comorbidities. ${ }^{104}$ Bariatric procedures have proven to enhance body metabolism independent of weight loss, therefore, leading to an improvement in blood glycemic and pressure control. ${ }^{105}$ As NAFLD has been closely related to obesity and insulin resistance, further studies including the direct influence of these procedures on NAFLD patients who failed other therapeutic modalities may include satisfactory results (- Table 3 ). In 2020, a long-term prospective study published by Lassailly et al ${ }^{106}$ revealed that bariatric 
surgery-induced resolution in $84 \%$ of patients with NASH without worsening of fibrosis $(p<0.001)$ and the regression of fibrosis occurred in $70 \%$ of patients $(p<0.001)$ at 5 -years follow-up. ${ }^{106}$ This novel study uncovers some hidden benefits of bariatric procedures in reducing liver-related mortalities. ${ }^{106}$ However, the safety and risks of these procedures should be weighed against the benefits in improving NASH levels before considering them as first-line therapy. Additionally, further broad cohort studies to evaluate survival rates following bariatric procedure should be considered. ${ }^{106}$

\section{Sleeve Gastrectomy}

Sleeve gastrectomy (SG) is a restrictive bariatric procedure that involves a resection of two-thirds of the stomach's greater curvature and gastric fundus creating a long tubular gastric conduit running along the lesser curvature. ${ }^{107}$ This results in increased satiation and a reduction in appetite by diminishing the gastric capacity, therefore, facilitating body weight loss. In 2018, SG continued to be the most common bariatric procedure performed in the United States, almost encompassing $61 \%{ }^{103}$ Its significant effect on weight loss has been extensively studied in multiple meta-analyses, ${ }^{78,108,109}$ and the expected \%TWL is $23.4 \%$ over a year. ${ }^{110}$ Moreover, the ameliorating effect on NAFLD and liver profile overall has been studied. A systematic review and a meta-analysis conducted by Baldwin et al ${ }^{108}$ compared Roux-en-Y Gastric Bypass (RYGB) and SG, with their impacts on liver histology, NAS, and NFS. The patients who underwent SG experienced a significant reduction in NAS of $-2.3(p<0.00001)$ without any differences when compared with RYGB. Regarding NFS reduction, both procedures resulted in statistically significant difference $(p<0.00001)$ with a mean postoperative NFS reduction of -0.9 , when comparing each type of procedure individually, LSG resulted in a mean reduction of $-0.7(p=0.07)$ while RYGB had -1.0 reduction. ${ }^{108}$ According to a prospective study conducted on 94 patients with obesity by Salman et al, ${ }^{111}$ SG resulted in a statistically significant weight loss with a marked reduction of BMI from $44.54 \pm 5.45 \mathrm{~kg} / \mathrm{m}^{2}$ to $34.23 \pm 2.66 \mathrm{~kg} / \mathrm{m}^{2}(p<0.001)$ in 12 months after the surgery. Additionally, the NAS score significantly decreased from $5.2 \pm 1.96$ to $2.63 \pm 1.55$ in 1 year $(p<0.001) .{ }^{111}$ These findings support the utility of SG as part of a treatment regimen for obesity complicated with NAFLD.

\section{Roux-en-Y Gastric Bypass}

RYGB is a surgical intervention with a combined restrictive and malabsorptive effects. It is considered to be a gastrointestinal reconstructive procedure performed by connecting a limb of the small intestine to a small gastric pouch forming a shape of the letter "Y." 112 Bypassing a portion of the large stomach pouch and proximal small intestine reduces the amount of nutrients and calories being absorbed, therefore, creating a caloric deficit that will lead to weight loss. ${ }^{112}$ RYGB represents the second most commonly performed bariatric procedure in the United States for the year 2018, after SG comprising $17 \%(42,945 / 252,000){ }^{103}$ The expected \%TBWL is $30.9 \%$ over a year. ${ }^{110}$ Multiple meta-analyses have been performed to understand its effect on NAFLD. ${ }^{78,108}$ Fakhry et al ${ }^{78}$ conducted a meta-analysis on 21 RCT studies (12/21 were for RYGB) of 2,374 patients investigating the impact of RYGB on NAFLD and comparing it to other types of procedures. They noticed that a higher number of RYGB patients had a regression in NAFLD compared with other surgeries. Precisely, the pooled portion of RYGB candidates who had improvement or complete resolution of steatosis, steatohepatitis, and fibrosis were 91,60 , and $31 \%$, respectively. ${ }^{78}$ Another previously mentioned meta-analysis, Baldwin et al, ${ }^{108}$ revealed that in only seven out of 20 studies had reported the NAS outcome pre- and postoperatively. Following RYGB surgery, a significant reduction in NAS and NFS of $-2.8(p<0.00001)$ and $-1.0(p<0.00001)$ was accomplished, respectively. However, the head-to-head comparison in NAS between RYGB and SG yielded an insignificant difference, while favoring RYGB results. Overall, their analysis concluded that both RYGB and SG had a positive impact on the liver profile, with failed superiority between the two types of procedures. $^{108}$

\section{Acute Liver Decompensation following Bariatric Surgery} As the main indication of bariatric procedures is severe obesity, with or without comorbidities, the coincidence of NAFLD in these patients should be considered. In fact, this indicates the presence of various degrees of liver impairment in those undergoing surgery, warranting prompt, and cautious preoperative surveillance. Surgery is contraindicated in specific liver conditions such as acute liver failure, viral and alcoholic hepatitis. ${ }^{113}$ Regarding the prevalence of NAFLD in patients scheduled for bariatric surgery, a prospective crosssectional study ${ }^{114}$ conducted on 184 patients revealed that $84 \%$ of them had a degree of NAFLD (22\% steatosis; $30.8 \%$ mild steatohepatitis; and 32\% moderate-severe steatohepatitis). Praveenraj et al ${ }^{115}$ demonstrated almost similar findings when studying 134 patients, $65.7 \%$ had NAFLD (26.1\% steatosis; $33.6 \%$ steatohepatitis; and $31.3 \%$ hepatic fibrosis). ${ }^{115}$ It is noticeable that most patients in both studies have an advanced level of the disease, possessing a higher risk for liver-related mortality. Following bariatric surgery, there is evidence that NAFLD might worsen in up to $12 \%$ of patients and might get to fibrosis. ${ }^{116}$

Furthermore, patients undergoing malabsorptive-dominant bariatric surgeries are at risk of developing acute hepatic impairment. ${ }^{117}$ Consequently, rapidly progressive liver damage might arise following bariatric surgery as a result of drastic weight loss and subsequent protein malnourishment prompting excessive lipolysis, which increases liver metabolism of long-chain fatty acids from visceral adipose tissue. ${ }^{118}$ Therefore, thorough preoperative evaluation, weighing the risks (short- and long-term complications) and benefits (weight reduction and comorbidity resolution) in each patient individually, along with proper counseling on the lifelong follow-up commitment are vital steps before considering such invasive surgeries.

\section{Conclusion}

NAFLD is the most common chronic liver disease in the developed world, and it is associated with several metabolic 


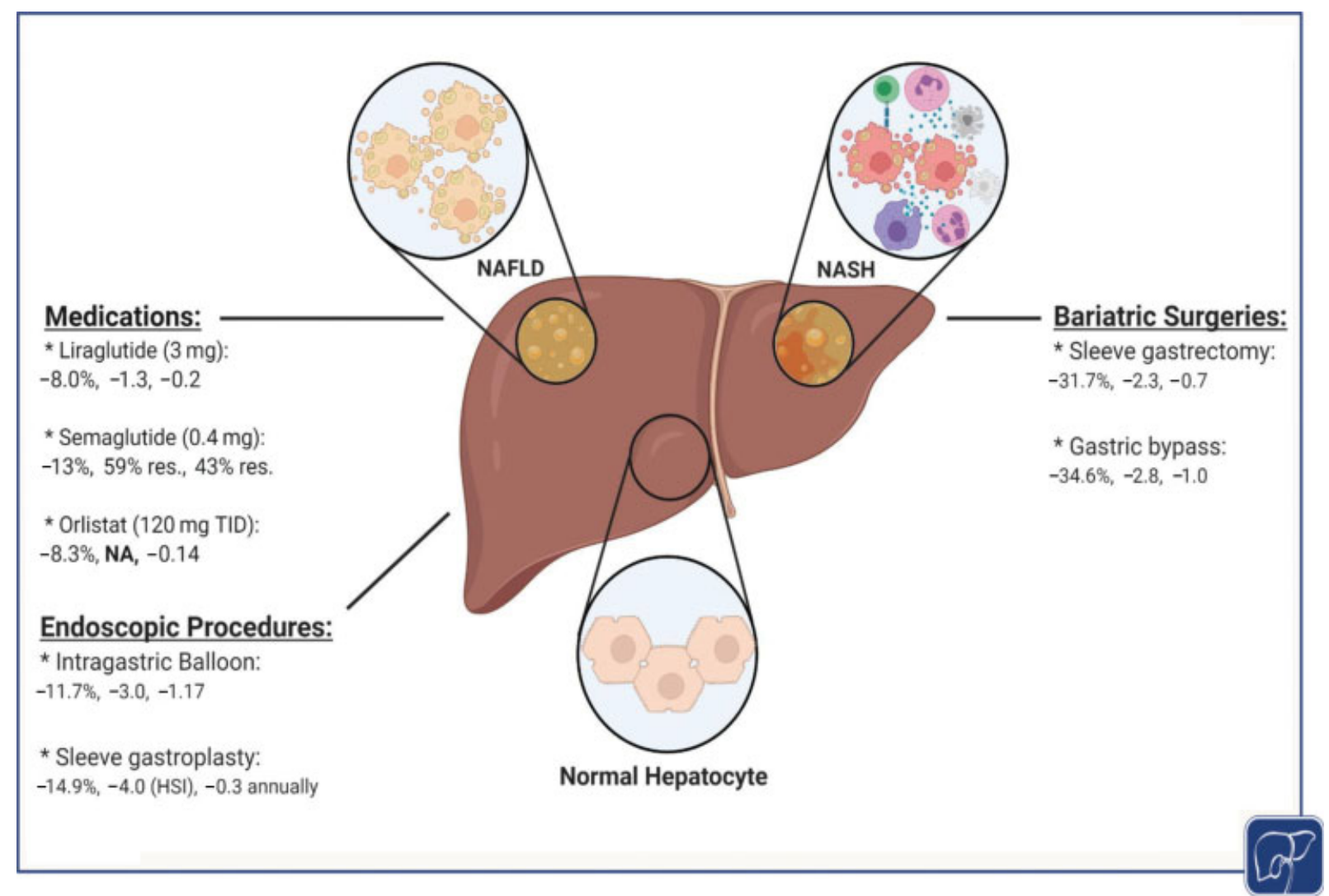

Fig. 2 An illustration demonstrating the effect of various weight loss interventions on \%TBWL, NAS, and NFS improvements, respectively. "res." indicates complete resolution of NASH and fibrosis, sequentially. NASH, nonalcoholic steatohepatitis; NFS, nonalcoholic fatty liver disease fibrosis score; TBWL, total body weight loss.

comorbidities. Prompt intervention upon diagnosis is crucial to reduce the progression of the disease into an advanced stage. As weight loss is the mainstay in treating NAFLD, this opens the door for a wide variety of possible therapeutic approaches that can be tailored based on the patient's characteristics. This includes diet, exercise, antiobesity medications, and endoscopic and surgical bariatric procedures (-Fig. 2). Medications and bariatric interventions provide more sustainable weight loss, which has been evident to have some improvement in the NAFLD activity score and fibrosis. The exact efficacy of these interventions needs to be further evaluated in standardized and well-designed randomized-controlled clinical trials.

\section{Main Concepts and Learning Points}

- Most of the available interventions that lead to $\geq 5$ to $10 \%$ weight loss result in substantial improvement in nonalcoholic fatty liver disease activity (NAFLD) scores (NAS) and NAFLD fibrosis scores (NFS) and even lead to complete NAFLD resolution.

- Antiobesity medications, especially liraglutide, semaglutide, and orlistat, improve NAS and NFS scores.

- Bariatric endoscopy and surgery achieved the highest and most sustainable weight loss and resulted in significant improvement in NAS and fibrosis scores.
- Bariatric endoscopy and surgery provide higher odds for NAFLD resolution.

\section{Funding}

A.A. is supported by NIH (NIH K23-DK114460, C-Sig P30DK84567), ANMS Career Development Award, Mayo Clinic Center for Individualized Medicine-Gerstner Career Development Award and Magnus Trust.

\section{Conflicts of Interest}

A.A. is a stockholder in Gila Therapeutics, and Phenomix Sciences; he serves as a consultant for Rhythm Pharmaceuticals, General Mills.

\section{References}

1 Kyle TK, Dhurandhar EJ, Allison DB. Regarding obesity as a disease: evolving policies and their implications. Endocrinol Metab Clin North Am 2016;45(03):511-520

2 Holly JMP, Biernacka K, Perks CM. Systemic metabolism, its regulators, and cancer: past mistakes and future potential. Front Endocrinol (Lausanne) 2019;10:65

3 Flegal KM, Kit BK, Orpana H, Graubard BI. Association of all-cause mortality with overweight and obesity using standard body mass index categories: a systematic review and meta-analysis. JAMA 2013;309(01):71-82

4 Adult Obesity Facts. CDC Published 2020. Accessed April 7, 2021 at: https://www.cdc.gov/obesity/data/adult.html 
5 Center of Disease Control. Accessed April 5, 2021 at: http://www. cdc.gov/media/pressrel/2008/r080624.htm

6 Wang Y, Beydoun MA, Liang L, Caballero B, Kumanyika SK. Will all Americans become overweight or obese? Estimating the progression and cost of the US obesity epidemic. Obesity (Silver Spring) 2008;16(10):2323-2330

7 Camilleri M, Malhi H, Acosta A. Gastrointestinal complications of obesity. Gastroenterology 2017;152(07):1656-1670

8 Seto WK. Chronic hepatitis B and metabolic risk factors: a call for rigorous longitudinal studies. World J Gastroenterol 2019;25 (03):282-286

9 Adams LA, Angulo P, Lindor KD. Nonalcoholic fatty liver disease. CMAJ 2005;172(07):899-905

10 Mitra S, De A, Chowdhury A. Epidemiology of non-alcoholic and alcoholic fatty liver diseases. Transl Gastroenterol Hepatol 2020; 5:16

11 Kanwal F, Kramer JR, Duan Z, Yu X, White D, El-Serag HB. Trends in the burden of nonalcoholic fatty liver disease in a United States cohort of veterans. Clin Gastroenterol Hepatol 2016;14(02): 301-8.e1, 2

12 Divella R, Mazzocca A, Daniele A, Sabbà C, Paradiso A. Obesity, nonalcoholic fatty liver disease and adipocytokines network in promotion of cancer. Int J Biol Sci 2019;15(03):610-616

13 Dai W, Ye L, Liu A, et al. Prevalence of nonalcoholic fatty liver disease in patients with type 2 diabetes mellitus: a metaanalysis. Medicine (Baltimore) 2017;96(39):e8179

14 Buzzetti E, Pinzani M, Tsochatzis EA. The multiple-hit pathogenesis of non-alcoholic fatty liver disease (NAFLD). Metabolism 2016;65(08):1038-1048

15 Dumitrascu DL, Neuman MG. Non-alcoholic fatty liver disease: an update on diagnosis. Clujul Med 2018;91(02):147-150

16 Brunt EM, Kleiner DE, Wilson LA, Belt P, Neuschwander-Tetri BA, Network NCRNASH Clinical Research Network (CRN) Nonalcoholic fatty liver disease (NAFLD) activity score and the histopathologic diagnosis in NAFLD: distinct clinicopathologic meanings. Hepatology 2011;53(03):810-820

17 Angulo P, Hui JM, Marchesini G, et al. The NAFLD fibrosis score: a noninvasive system that identifies liver fibrosis in patients with NAFLD. Hepatology 2007;45(04):846-854

18 Hashemi S-A, Alavian S-M, Gholami-Fesharaki M. Assessment of transient elastography (FibroScan) for diagnosis of fibrosis in non-alcoholic fatty liver disease: a systematic review and metaanalysis. Caspian J Intern Med 2016;7(04):242-252

19 Loomba R, Cui J, Wolfson T, et al. Novel 3D magnetic resonance elastography for the noninvasive diagnosis of advanced fibrosis in NAFLD: a prospective study. Am J Gastroenterol 2016;111 (07):986-994

20 Wang XM, Zhang XJ, Ma L. Diagnostic performance of magnetic resonance technology in detecting steatosis or fibrosis in patients with nonalcoholic fatty liver disease: a meta-analysis. Medicine (Baltimore) 2018;97(21):e10605

21 Nalbantoglu IL, Brunt EM. Role of liver biopsy in nonalcoholic fatty liver disease. World J Gastroenterol 2014;20(27):9026-9037

22 Dunn W, Xu R, Wingard DL, et al. Suspected nonalcoholic fatty liver disease and mortality risk in a population-based cohort study. Am J Gastroenterol 2008;103(09):2263-2271

23 Ampuero J, Aller R, Gallego-Durán R, et al; HEPAmet Registry. Significant fibrosis predicts new-onset diabetes mellitus and arterial hypertension in patients with NASH. J Hepatol 2020;73 (01):17-25

24 Ganguli S, DeLeeuw P, Satapathy SK. A review of current and upcoming treatment modalities in non-alcoholic fatty liver disease and non-alcoholic steatohepatitis. Hepat Med 2019; 11:159-178

25 Acosta A, Streett S, Kroh MD, et al. White Paper AGA: POWERpractice guide on obesity and weight management, education, and resources. Clin Gastroenterol Hepatol 2017;15(05):631-649.e10
26 Hannah WN Jr, Harrison SA. Effect of weight loss, diet, exercise, and bariatric surgery on nonalcoholic fatty liver disease. Clin Liver Dis 2016;20(02):339-350

27 St George A, Bauman A, Johnston A, Farrell G, Chey T, George J. Effect of a lifestyle intervention in patients with abnormal liver enzymes and metabolic risk factors. J Gastroenterol Hepatol 2009;24(03):399-407

28 Gepner Y, Shelef I, Komy O, et al. The beneficial effects of Mediterranean diet over low-fat diet may be mediated by decreasing hepatic fat content. J Hepatol 2019;71(02):379-388

29 Sun $\mathrm{W}-\mathrm{H}$, Song $\mathrm{M}-\mathrm{Q}$ Jiang $\mathrm{C}-\mathrm{Q}$ et al. Lifestyle intervention in non-alcoholic fatty liver disease in Chengyang District, Qingdao, China. World J Hepatol 2012;4(07):224-230

30 Promrat K, Kleiner DE, Niemeier HM, et al. Randomized controlled trial testing the effects of weight loss on nonalcoholic steatohepatitis. Hepatology 2010;51(01):121-129

31 Eckard C, Cole R, Lockwood J, et al. Prospective histopathologic evaluation of lifestyle modification in nonalcoholic fatty liver disease: a randomized trial. Therap Adv Gastroenterol 2013;6 (04):249-259

32 Ueno T, Sugawara H, Sujaku K, et al. Therapeutic effects of restricted diet and exercise in obese patients with fatty liver. J Hepatol 1997;27(01):103-107

33 Yasutake K, Nakamuta M, Shima Y, et al. Nutritional investigation of non-obese patients with non-alcoholic fatty liver disease: the significance of dietary cholesterol. Scand J Gastroenterol 2009; 44(04):471-477

34 Assy N, Nasser G, Kamayse I, et al. Soft drink consumption linked with fatty liver in the absence of traditional risk factors. Can J Gastroenterol 2008;22(10):811-816

35 Musso G, Cassader M, Rosina F, Gambino R. Impact of current treatments on liver disease, glucose metabolism and cardiovascular risk in non-alcoholic fatty liver disease (NAFLD): a systematic review and meta-analysis of randomised trials. Diabetologia 2012;55(04):885-904

36 Vilar-Gomez E, Martinez-Perez Y, Calzadilla-Bertot L, et al. Weight loss through lifestyle modification significantly reduces features of nonalcoholic steatohepatitis. Gastroenterology 2015; 149(02):367-78.e5, quiz e14-e15

37 Sacks FM, Bray GA, Carey VJ, et al. Comparison of weight-loss diets with different compositions of fat, protein, and carbohydrates. N Engl J Med 2009;360(09):859-873

38 Papamiltiadous ES, Roberts SK, Nicoll AJ, et al. A randomised controlled trial of a Mediterranean Dietary Intervention for Adults with Non Alcoholic Fatty Liver Disease (MEDINA): study protocol. BMC Gastroenterol 2016;16:14

39 Eslamparast T, Tandon P, Raman M. Dietary composition independent of weight loss in the management of non-alcoholic fatty liver disease. Nutrients 2017;9(08):E800

40 Ryan MC, Itsiopoulos C, Thodis T, et al. The Mediterranean diet improves hepatic steatosis and insulin sensitivity in individuals with non-alcoholic fatty liver disease. J Hepatol 2013;59(01): 138-143

41 Riebe D, Franklin BA, Thompson PD, et al. Updating ACSM's recommendations for exercise preparticipation health screening. Med Sci Sports Exerc 2015;47(11):2473-2479

42 Jensen MD, Ryan DH, Apovian CM, et al; American College of Cardiology/American Heart Association Task Force on Practice Guidelines Obesity Society. 2013 AHA/ACC/TOS guideline for the management of overweight and obesity in adults: a report of the American College of Cardiology/American Heart Association Task Force on Practice Guidelines and The Obesity Society. J Am Coll Cardiol 2014;63(25 Pt B):2985-3023

43 Heymsfield SB, Wadden TA. Mechanisms, pathophysiology, and management of obesity. N Engl J Med 2017;376(15):1492

44 Heymsfield SB, Wadden TA. Mechanisms, pathophysiology, and management of obesity. N Engl J Med 2017;376(03):254-266 
45 Ochner CN, Tsai AG, Kushner RF, Wadden TA. Treating obesity seriously: when recommendations for lifestyle change confront biological adaptations. Lancet Diabetes Endocrinol 2015;3(04): 232-234

46 Hall KD. Metabolic adaptations to weight loss. Obesity (Silver Spring) 2018;26(05):790-791

47 Daneschvar HL, Aronson MD, Smetana GW. FDA-approved antiobesity drugs in the United States. Am J Med 2016;129(08):879. e1-879.e6

48 Gryskiewicz KA, Coleman CI. Exenatide. Formulary 2005;40(03): 86

49 Pi-Sunyer X, Astrup A, Fujioka K, et al; SCALE Obesity and Prediabetes NN8022-1839 Study Group. A randomized, controlled trial of $3.0 \mathrm{mg}$ of liraglutide in weight management. $\mathrm{N}$ Engl J Med 2015;373(01):11-22

50 Iepsen EW, Torekov SS, Holst JJ. Liraglutide for type 2 diabetes and obesity: a 2015 update. Expert Rev Cardiovasc Ther 2015;13 (07):753-767

51 Armstrong MJ, Gaunt P, Aithal GP, et al; LEAN trial team. Liraglutide safety and efficacy in patients with non-alcoholic steatohepatitis (LEAN): a multicentre, double-blind, randomised, placebo-controlled phase 2 study. Lancet 2016;387(10019):679-690

52 Newsome PN, Buchholtz K, Cusi K, et al. A placebo-controlled trial of subcutaneous semaglutide in nonalcoholic steatohepatitis. N Engl J Med 2021;384(12):1113-1124

53 Guerciolini R. Mode of action of orlistat. Int J Obes Relat Metab Disord 1997;21(Suppl 3):S12-S23

54 Hutton B, Fergusson D. Changes in body weight and serum lipid profile in obese patients treated with orlistat in addition to a hypocaloric diet: a systematic review of randomized clinical trials. Am J Clin Nutr 2004;80(06):1461-1468

55 Assy N, Hussein O, Abassi Z. Weight loss induced by orlistat reverses fatty infiltration and improves hepatic fibrosis in obese patients with non-alcoholic steatohepatitis. Gut 2007;56(03):443-444

56 Harrison SA, Fecht W, Brunt EM, Neuschwander-Tetri BA. Orlistat for overweight subjects with nonalcoholic steatohepatitis: a randomized, prospective trial. Hepatology 2009;49(01):80-86

57 Harrison SA, Fincke C, Helinski D, Torgerson S, Hayashi P. A pilot study of orlistat treatment in obese, non-alcoholic steatohepatitis patients. Aliment Pharmacol Ther 2004;20(06):623-628

58 Kelley DE, Kuller LH, McKolanis TM, Harper P, Mancino J, Kalhan S. Effects of moderate weight loss and orlistat on insulin resistance, regional adiposity, and fatty acids in type 2 diabetes. Diabetes Care 2004;27(01):33-40

59 Zelber-Sagi S, Kessler A, Brazowsky E, et al. A double-blind randomized placebo-controlled trial of orlistat for the treatment of nonalcoholic fatty liver disease. Clin Gastroenterol Hepatol 2006;4(05):639-644

60 Greydanus DE, Bricker LA, Feucht C. Pharmacotherapy for obese adolescents. Pediatr Clin North Am 2011;58(01):139-153, xi.

61 Rothman RB, Baumann MH. Appetite suppressants, cardiac valve disease and combination pharmacotherapy. Am J Ther 2009;16 (04):354-364

62 Cosentino G, Conrad AO, Uwaifo GI. Phentermine and topiramate for the management of obesity: a review. Drug Des Devel Ther 2011;7:267-278

63 Verrotti A, Scaparrotta A, Agostinelli S, Di Pillo S, Chiarelli F, Grosso S. Topiramate-induced weight loss: a review. Epilepsy Res 2011;95(03):189-199

64 Astrup A, Caterson I, Zelissen P, et al. Topiramate: long-term maintenance of weight loss induced by a low-calorie diet in obese subjects. Obes Res 2004;12(10):1658-1669

65 Lonneman DJ Jr, Rey JA, McKee BD. Phentermine/Topiramate extended-release capsules (qsymia) for weight loss. P\&T 2013; 38(08):446-452

66 Acosta A, Camilleri M, Shin A, et al. Quantitative gastrointestinal and psychological traits associated with obesity and response to weight-loss therapy. Gastroenterology 2015;148(03):537-546.e4
67 Allison DB, Gadde KM, Garvey WT, et al. Controlled-release phentermine/topiramate in severely obese adults: a randomized controlled trial (EQUIP). Obesity (Silver Spring) 2012;20(02): 330-342

68 Gadde KM, Xiong GL. Bupropion for weight reduction. Expert Rev Neurother 2007;7(01):17-24

69 Greenway FL, Whitehouse MJ, Guttadauria M, et al. Rational design of a combination medication for the treatment of obesity. Obesity (Silver Spring) 2009;17(01):30-39

70 Christou GA, Kiortsis DN. The efficacy and safety of the naltrexone/bupropion combination for the treatment of obesity: an update. Hormones (Athens) 2015;14(03):370-375

71 Sherman MM, Ungureanu S, Rey JA. Naltrexone/Bupropion ER (Contrave): newly approved treatment option for chronic weight management in obese adults. P\&T 2016;41(03):164-172

72 FDA Food and Drug Administration. FDA approves weightmanagement drug Contrave. 2014. Published 2014. Accessed April 7, 2021 at: www.fda.gov/newsevents/newsroom/pressannouncements/ucm413896.htm

73 Greenway FL, Fujioka K, Plodkowski RA, et al; COR-I Study Group. Effect of naltrexone plus bupropion on weight loss in overweight and obese adults (COR-I): a multicentre, randomised, doubleblind, placebo-controlled, phase 3 trial. Lancet 2010;376 (9741):595-605

74 Allison Winokur AH, Dybala C, Lam H, Chen S, Naga PChalasani. Naltrexone/bupropion extended-release $32 \mathrm{mg} / 360 \mathrm{mg}$ significantly improves liver enzymes in obese/overweight individuals with elevated liver enzymes. Hepatology 2015;62:1268A

75 Bajaj HS, Burrows M, Blavignac J, et al. Extended-release naltrexone/bupropion and liver health: pooled, post hoc analysis from four randomized controlled trials. Diabetes Obes Metab 2021;23(03):861-865

76 Abu Dayyeh BK, Bazerbachi F, Graupera I, Cardenas A. Endoscopic bariatric and metabolic therapies for non-alcoholic fatty liver disease. J Hepatol 2019;71(06):1246-1248

77 Martins C, Strømmen M, Stavne OA, Nossum R, Mårvik R, Kulseng B. Bariatric surgery versus lifestyle interventions for morbid obesity-changes in body weight, risk factors and comorbidities at 1 year. Obes Surg 2011;21(07):841-849

78 Fakhry TK, Mhaskar R, Schwitalla T, Muradova E, Gonzalvo JP, Murr MM. Bariatric surgery improves nonalcoholic fatty liver disease: a contemporary systematic review and meta-analysis. Surg Obes Relat Dis 2019;15(03):502-511

79 Pajot G, Calderon G, Acosta A. Endoscopic treatments for obesity. Curr Treat Options Gastroenterol 2017;15(04):660-675

80 Ali MR, Moustarah F, Kim JJAmerican Society for Metabolic and Bariatric Surgery Clinical Issues Committee. American Society for Metabolic and Bariatric Surgery position statement on intragastric balloon therapy endorsed by the Society of American Gastrointestinal and Endoscopic Surgeons. Surg Obes Relat Dis 2016;12(03):462-467

81 Gaur S, Levy S, Mathus-Vliegen L, Chuttani R. Balancing risk and reward: a critical review of the intragastric balloon for weight loss. Gastrointest Endosc 2015;81(06):1330-1336

82 Bazerbachi F, Haffar S, Sawas T, et al. Fluid-filled versus gas-filled intragastric balloons as obesity interventions: a network metaanalysis of randomized trials. Obes Surg 2018;28(09):2617-2625

83 Kim SH, Chun HJ, Choi HS, Kim ES, Keum B, Jeen YT. Current status of intragastric balloon for obesity treatment. World J Gastroenterol 2016;22(24):5495-5504

84 ORBERA $^{\mathrm{TM}}$ Intragastric Balloon System-P140008. Published. Accessed April 6, 2021 at: http://wayback.archive-it.org/7993/ 20170111141139/http:/www.fda.gov/MedicalDevices/ProductsandMedicalProcedures/DeviceApprovalsandClearances/Recently-ApprovedDevices/ucm457416.htm2015

85 NASH News March. 2021-Recognizing NASH patient advocacy. Accessed April 5, 2021 at: https://www.globalliver.org/news/ 2021/nash-news-march 
86 Bazerbachi F, Vargas EJ, Rizk M, et al. Intragastric balloon placement induces significant metabolic and histologic improvement in patients with nonalcoholic steatohepatitis. Clin Gastroenterol Hepatol 2020;19(01):146-154

87 Popov VB, Thompson CC, Kumar N, Ciarleglio MM, Deng Y, Laine L. Effect of intragastric balloons on liver enzymes: a systematic review and meta-analysis. Dig Dis Sci 2016;61(09):2477-2487

88 Chandan S, Mohan BP, Khan SR, et al. Efficacy and safety of intragastric balloon (IGB) in non-alcoholic fatty liver disease (NAFLD): a Comprehensive review and meta-analysis. Obes Surg 2021;31(03):1271-1279

89 Abu Dayyeh BK, Edmundowicz SA, Jonnalagadda S, et al; ASGE Bariatric Endoscopy Task Force ASGE Technology Committee. Endoscopic bariatric therapies. Gastrointest Endosc 2015;81 (05):1073-1086

90 Lopez-Nava G, Galvão MP, Bautista-Castaño I, Jimenez-Baños A, Fernandez-Corbelle JP. Endoscopic sleeve gastroplasty: how I do it? Obes Surg 2015;25(08):1534-1538

91 Abu Dayyeh BK, Acosta A, Camilleri M, et al. Endoscopic sleeve gastroplasty alters gastric physiology and induces loss of body weight in obese individuals. Clin Gastroenterol Hepatol 2017;15 (01):37-43.e1

92 Sharaiha RZ, Kumta NA, Saumoy M, et al. Endoscopic sleeve gastroplasty significantly reduces body mass index and metabolic complications in obese patients. Clin Gastroenterol Hepatol 2017;15(04):504-510

93 Singh S, Hourneaux de Moura DT, Khan A, Bilal M, Ryan MB, Thompson CC. Safety and efficacy of endoscopic sleeve gastroplasty worldwide for treatment of obesity: a systematic review and meta-analysis. Surg Obes Relat Dis 2020;16(02):340-351

94 Hajifathalian K, Mehta A, Ang B, et al. Improvement in insulin resistance and estimated hepatic steatosis and fibrosis after endoscopic sleeve gastroplasty. Gastrointest Endosc 2021;93(05): $1110-1118$

95 Hedjoudje A, Abu Dayyeh BK, Cheskin LJ, et al. Efficacy and safety of endoscopic sleeve gastroplasty: a systematic review and metaanalysis. Clin Gastroenterol Hepatol 2020;18(05):1043-1053.e4

96 van Baar ACG, Holleman F, Crenier L, et al. Endoscopic duodenal mucosal resurfacing for the treatment of type 2 diabetes mellitus: one year results from the first international, open-label, prospective, multicentre study. Gut 2020;69(02):295-303

97 Theodorakis MJ, Carlson O, Michopoulos S, et al. Human duodenal enteroendocrine cells: source of both incretin peptides, GLP-1 and GIP. Am J Physiol Endocrinol Metab 2006;290(03):E550-E559

98 Verdam FJ, Greve JW, Roosta S, et al. Small intestinal alterations in severely obese hyperglycemic subjects. J Clin Endocrinol Metab 2011;96(02):E379-E383

99 de Moura EGH, Ponte-Neto AM, Tsakmaki A, Aiello VD, Bewick GA, Brunaldi VO. Histologic assessment of the intestinal wall following duodenal mucosal resurfacing (DMR): a new procedure for the treatment of insulin-resistant metabolic disease. Endosc Int Open 2019;7(05):E685-E690

100 Rajagopalan H, Cherrington AD, Thompson CC, et al. Endoscopic duodenal mucosal resurfacing for the treatment of type 2 diabetes: 6-month interim analysis from the first-in-human proof-of-concept study. Diabetes Care 2016;39(12):2254-2261

101 de Oliveira GHP, de Moura DTH, Funari MP, et al. Metabolic effects of endoscopic duodenal mucosal resurfacing: a systematic review and meta-analysis. Obes Surg 2021;31(03):1304-1312

102 Safety \& effectiveness of duodenal mucosal resurfacing (DMR) using the Revita ${ }^{\mathrm{TM}}$ system in treatment of type 2 diabetes. Accessed April 7, 2021 at: https://clinicaltrials.gov/ct2/show/ NCT03653091
103 English WJ, DeMaria EJ, Hutter MM, et al. American Society for Metabolic and Bariatric Surgery 2018 estimate of metabolic and bariatric procedures performed in the United States. Surg Obes Relat Dis 2020;16(04):457-463

104 Buchwald H, Avidor Y, Braunwald E, et al. Bariatric surgery: a systematic review and meta-analysis. JAMA 2004;292(14): 1724-1737

105 Wolfe BM, Kvach E, Eckel RH. Treatment of obesity: weight loss and bariatric surgery. Circ Res 2016;118(11):1844-1855

106 Lassailly G, Caiazzo R, Ntandja-Wandji LC, et al. Bariatric surgery provides long-term resolution of nonalcoholic steatohepatitis and regression of fibrosis. Gastroenterology 2020;159(04): 1290-1301.e5

107 Benaiges D, Más-Lorenzo A, Goday A, et al. Laparoscopic sleeve gastrectomy: more than a restrictive bariatric surgery procedure? World J Gastroenterol 2015;21(41):11804-11814

108 Baldwin D, Chennakesavalu M, Gangemi A. Systematic review and meta-analysis of Roux-en-Y gastric bypass against laparoscopic sleeve gastrectomy for amelioration of NAFLD using four criteria. Surg Obes Relat Dis 2019;15(12):2123-2130

109 Shoar S, Saber AA. Long-term and midterm outcomes of laparoscopic sleeve gastrectomy versus Roux-en-Y gastric bypass: a systematic review and meta-analysis of comparative studies. Surg Obes Relat Dis 2017;13(02):170-180

110 Maciejewski ML, Arterburn DE, Van Scoyoc L, et al. Bariatric surgery and long-term durability of weight loss. JAMA Surg 2016;151(11):1046-1055

111 Salman MA, Salman AA, Abdelsalam A, et al. Laparoscopic sleeve gastrectomy on the horizon as a promising treatment modality for NAFLD. Obes Surg 2020;30(01):87-95

112 Björklund P, Laurenius A, Een E, Olbers T, Lönroth H, Fändriks L. Is the Roux limb a determinant for meal size after gastric bypass surgery? Obes Surg 2010;20(10):1408-1414

113 Friedman LS. Surgery in the patient with liver disease. Trans Am Clin Climatol Assoc 2010;121:192-204, discussion 205

114 Morita S, Neto DdeS, Morita FHA, Morita NK, Lobo SMA. Prevalence of non-alcoholic fatty liver disease and steatohepatitis risk factors in patients undergoing bariatric surgery. Obes Surg 2015; 25(12):2335-2343

115 Praveenraj P, Gomes RM, Kumar S, et al. Prevalence and predictors of non-alcoholic fatty liver disease in morbidly obese south Indian patients undergoing bariatric surgery. Obes Surg 2015;25(11):2078-2087

116 Lee Y, Doumouras AG, Yu J, et al. Complete resolution of nonalcoholic fatty liver disease after bariatric surgery: a systematic review and meta-analysis. Clin Gastroenterol Hepatol 2019; 17(06):1040-1060.e11

117 Mahawar KK, Parmar C, Graham Y, et al. Monitoring of liver function tests after Roux-en-Y gastric bypass: an examination of evidence base. Obes Surg 2016;26(10):2516-2522

118 Mocanu I, Carvalhana S, Costa P, Palma R. Liver failure after bariatric surgery-clinical case and literature review. J Gastroenterol Metabol 2018;1:104

119 Wang H, Wang L, Cheng Y, Xia Z, Liao Y, Cao J. Efficacy of orlistat in non-alcoholic fatty liver disease: a systematic review and meta-analysis. Biomed Rep 2018;9(01):90-96

120 Plodkowski RA, McGarvey ME, Reisinger-Kindle K, et al. Obesity management: clinical review and update of the pharmacologic treatment options. Fed Pract 2016;33(01):6-16

121 Harpreet S, Bajaj MB, Blavignac J, et al. Extended-release naltrexone/bupropion and liver health: pooled, post-hoc analysis from 4 RCTs. Diabetes Obes Metab 2021;23(03): 861-865 